\title{
Building ceramics with improved thermal insulation parameters
}

\author{
Karol Rzepa ${ }^{1, a}$, Wojciech Wons ${ }^{1}$ and Manuela Reben ${ }^{1}$ \\ ${ }^{1}$ AGH University of Science and Technology
}

\begin{abstract}
One of the most important performance characteristics of masonry units is their high thermal insulation. There are many different ways to improve this parameter, however the most popular methods in case of ceramic masonry units are: addition of pore-creating raw materials and application of proper hole pattern. This study was an attempt to improve thermal insulation of ceramics by applying thermal insulation additives. Perlite dust created as a subgrain from expansion of perlite rock was used. Perlite subgrain is not very popular among consumers, that's why it's subjected to granulation to obtain coarse grain. The authors presented concept of direct application of perlite dust for the production of building ceramics with improved thermal insulation. Fineness of this additive is asset for molding of ceramic materials from plastic masses. Based on the results it was found that about $70 \%$ perlite by volume can be added to obtain material with a coefficient of heat conductivity of $0,37 \mathrm{~W} / \mathrm{mK}$. Higher content of this additive in ceramic mass causes deterioration of its rheological properties. Mass loses its plasticity, it tears up and formed green bodies are susceptible to deformation. During sintering perlite takes an active part in compaction process. Higher sintering dynamics is caused by: high content of alkali oxides in perlite and glass nature of perlite. Alkali oxides generate creation of liquid phase which intensifies mass compaction processes. Active role of perlite in sintering process causes good connection of its grains with clay groundwork which is important factor for mechanical parameters of ceramic materials. It was also noted that addition of perlite above $40 \%$ by volume of mass effectively neutralized negative effect of efflorescence in ceramic materials.
\end{abstract}

\section{Introduction}

The importance of renewable source based products for industrial applications becomes extremely visible in recent years with increasing emphasis on the environmental issues, waste disposal, and depleting non-renewable resources. Through innovative ideas in designing the fired building ceramics with dusty expanded perlite which can compete or even surpass with the existing materials on a cost-performance basis with the added advantage of eco-friendliness and thermo insulating properties. One of the most important challenges of future of building ceramics materials is the improvement of their thermo insulating properties, which leads to the reduction of energy consumptions of buildings in all their life phases, from construction to demolition [1]. Constant, or even increasing popularity of this trend shows not only economic justification associated with a decrease in demand for thermal energy, but also has a legal nature. Since 2009 in Poland there is an obligation to perform an energetic audits for new or modernized buildings [2]. Introduced law caused a natural increase in interest of building materials with a good thermal insulation parameters, including ceramics. In the field of thermal insulating of building ceramics there are several ways to improve thermal insulating properties:

1. Use of the additive for porosity increase like: sawdust, cellulose pulp, Styrofoam balls. During firing process these

\footnotetext{
${ }^{a}$ Corresponding author: krzepa@agh.edu.pl
}

components are burned, leaving pores which are centres of very high thermal insulation $[3,4,5]$.

2. Use of the lowest firing temperature for sintering without liquid phase. Liquid phase facilitates sintering process but it also causes flooding of pores which are important to provide thermal insulation of ceramic product.

3 . Use of the cavity system in the ceramic products which provide longer heat transfer through ceramic material. This assumption results from fact that ceramics is a material with inferior thermal insulation than the air contained in hollows $[6,7]$.

4. Use of the thermal insulating additives in ceramic masses. These additives are characterized by very good thermal insulation properties that is why their addition to masses or products improves this parameter [8].

5. Partial or total elimination of grouting, the binder made of mortar between masonry components. Binder is so called thermal bridge, through which heat rapidly flows inside wall. Vertical grouting is completely eliminated by usage of tongue and groove joints while horizontal grouting can be limited by grinding of surface and applying thin binder.

In this research an attempt to improve thermal insulation of building ceramics was made by using expanded perlite as a thermal insulating additive.

Perlite is effusive rock, basically mineral obsidian which can be commonly found in region of Mediterranean Basin. It was formed during underwater volcanic eruption, therefore it is a vitreous substance contains $2-5 \%$ water [9]. Natural perlite has a specific density between $2200 \mathrm{~kg} / \mathrm{m} 3$ 
and $2300 \mathrm{~kg} / \mathrm{m} 3$ [10], and it's not thermal insulating material but it can be transformed into one through the process of expansion. During heating process in the temperature of $850-1150^{\circ} \mathrm{C}$, water closed inside glassy phase undergoes rapid expansion [11]. This phenomenon is accompanied by micro-explosions and a dozen times increase in perlite's volume. As a result of the expansion process oval, irregular and glassy grains of cellular microstructure are created. Specific density of expanded perlite varies between $80 \mathrm{~kg} / \mathrm{m}^{3}$ to $240 \mathrm{~kg} / \mathrm{m}^{3}$ [12], also thermal conductivity $\lambda$ is $0,045-0,059 \mathrm{~W} / \mathrm{m} \cdot \mathrm{K}$. This material is resistant to chemical and biological corrosion and shows good sound absorption [13]. These and other features of expanded perlite causes its increasing popularity. Perlite also found application in the products of building ceramics [14]. It is used as a light-weight aggregate in concrete and plasters, also as good insulating material [15]. Moulders are often produced through pressing of semi-dry masses or dry masses involving perlite. Proper performance parameters are obtained by autoclaving or firing. Sample parameters of these materials are bulk density of $0,45-0,55 \mathrm{~g} / \mathrm{cm}^{3}$ and minimum compressive strength of $0,7 \mathrm{MPa}$.

In this paper an attempt to produce a perlite brick using plastic, wet method of forming has been made. This method is common in the production of fired building ceramics, because it allows the production of moulders with complex shapes, including products with a high proportion of cavities. The choice of this method requires the use of dusty expanded perlite. On the one hand it was economically justified, because perlite of such granulation is directly used in a small extent, and also is a low cost material [16]. Moreover, it does not require grinding and can be directly added to the plastic mass without substantial deterioration of operating parameters.

\section{Experimental}

A series of ceramic materials were prepared with different proportion of perlite in the raw material mixtures. Selected functional parameters of ceramic materials obtained were determined. In addition to perlite in the mixtures, the raw clay was used. Clay and perlite are characterized by the significantly different bulk density $\left(\rho_{\text {perlite }}=(87 \pm 2)\right.$ $\left.\mathrm{kg} / \mathrm{m} 3, \rho_{\text {clay }}=(1243 \pm 22) \mathrm{kg} / \mathrm{m} 3\right)$, thus the mixture compositions are given in volumetric and mass ratios (Table1).

Table 1. Symbols and compositions of clay-perlite masses.

\begin{tabular}{|c|c|c|c|c|}
\hline \multirow{2}{*}{$\begin{array}{c}\text { Symbol } \\
\text { of mass }\end{array}$} & \multicolumn{2}{|c|}{$\begin{array}{c}\text { Volumetric ratio } \\
{[\%]}\end{array}$} & \multicolumn{2}{c|}{ Mass ratio [\%] } \\
\cline { 2 - 5 } & perlite & lias clay & perlite & lias clay \\
\hline 0 & 0 & 100 & 0 & 100 \\
\hline P2 & 20 & 80 & 1,7 & 98,3 \\
\hline P4 & 40 & 60 & 4,5 & 95,5 \\
\hline P6 & 60 & 40 & 9,5 & 90,5 \\
\hline P7 & 70 & 30 & 14,0 & 86,0 \\
\hline P8 & 80 & 20 & 21,9 & 78,1 \\
\hline P9 & 90 & 10 & 38,6 & 61,4 \\
\hline
\end{tabular}

Ceramic materials were prepared in the following manner: after weighing the ingredients were dry-homogenized for 30 minutes in a tumbler mixers. Created mixtures were mixed with water until plastic mass was obtained. After 24 hour of homogenization different moulders from masses were formed as follow: 50x50x50 $\mathrm{mm}$ cubes, $15 \times 35 \times 50 \mathrm{~mm}$ bricks and $80 \mathrm{~mm}$ diameter rollers (for thermal conductivity test). Prepared moulders were initially dried under laboratory conditions first at the temperature of $20^{\circ} \mathrm{C}$ and $60 \%$ air humidity, then the moulders were dried in laboratory dryer up to the temperature of $105^{\circ} \mathrm{C}$. For dried moldings the necessary measurements to calculate the mixing water, the density after drying and drying shrinkage were made. After these measurements all moulders were fired at a maximum temperature of $950{ }^{\circ} \mathrm{C}$. Designs of the parameters before and after firing are included in [17]. All measurements were performed on 6 samples. Rollers prepared for the thermal conductivity test were grinded on the one side and all pollutants produced during the grinding process were removed with compressed air. In this study the non-stationary method was used thermal probe [18].

In order to clarify the influence of the perlite on sintering process of ceramic masses measurement in a high-temperature microscope was performed, as well as differential thermal analysis DTA combined with thermogravimetry TG, XRD phase analysis and SEM microstructure study. These tests were made only for the masses and materials marked as „P7" and „0".

High-temperature microscopy consists of recording the surface contour of samples and their shape changes during heating. Based on the test results, characteristic temperatures were determined:

- the beginning of sintering temperature (first shrinkage connected with sintering),

- the maximum of sintering temperature (maximum sintering shrinkage with no deformation effects),

- the temperature of softening point (first sample deformation, e.g. rounded corners).

The measurements were performed with use of high-temperature microscope Hesse Instruments. Cylindrical samples with dimensions of $\mathrm{d}=\mathrm{h}=3 \mathrm{~mm}$ were prepared in special manual press. The measurement was carried out in air with a constant heating rate of $10^{\circ} \mathrm{C} / \mathrm{min}$ to the maximum temperature of $1300^{\circ} \mathrm{C}$.

XRD (X-Ray Diffraction) analysis was used to determine the phase composition of materials (diffractometer PANalytical equipped with copper anode). Measurements were carried out with the following performance parameters: range from 10 to $702 \Theta$, step size 0,01, time per step 255,905 s.

Complementary research method used for additional analysis of phase composition was differential thermal analysis combined with thermogravimetry. DTA and TG measurements were performed in a STA 449F3 Jupiter Netzsch apparatus for starting materials and P7 ceramic mass. The test was conducted in an atmosphere of synthetic air with a flow of $40 \mathrm{ml} / \mathrm{min}$ and the heating rate of $15^{\circ} \mathrm{C} / \mathrm{min}$. Clay, perlite and ceramic mass samples were milled to a grain size below $0.06 \mathrm{~mm}$ and weighted in range from 85 to $95 \mathrm{mg}$. 
The morphology of samples tested was studied with use of scanning electron microscope SEM equipped with EDS microanalyzer. Fractured samples were sputtered with carbon before the measurements, which were performed in a high vacuum.

\section{Results and discussion}

\subsection{Parameters of ceramic bulks}

Averages of measured parameters with standard errors (confidence level of 0,95 ) of 6 samples for each mass before firing are shown in the table 2 .

Table 2. Parameters of clay-perlite masses.

\begin{tabular}{|c|c|c|c|}
\hline $\begin{array}{c}\text { Symbol } \\
\text { of mass }\end{array}$ & $\begin{array}{c}\text { Mixing water } \\
{[\mathbf{\%}]}\end{array}$ & $\begin{array}{c}\text { Drying } \\
\text { shrinkage }[\mathbf{\%}]\end{array}$ & $\begin{array}{c}\text { Bulk density } \\
{\left[\mathbf{k g} / \mathbf{m}^{\mathbf{3}}\right]}\end{array}$ \\
\hline 0 & $20,0 \pm 0,1$ & $9,3 \pm 0,3$ & $2,04 \pm 0,01$ \\
\hline P2 & $19,5 \pm 0,1$ & $8,1 \pm 0,3$ & $1,94 \pm 0,02$ \\
\hline P4 & $20,9 \pm 0,1$ & $7,4 \pm 0,3$ & $1,78 \pm 0,01$ \\
\hline P6 & $25,3 \pm 0,2$ & $7,7 \pm 0,3$ & $1,53 \pm 0,01$ \\
\hline P7 & $29,5 \pm 0,1$ & $7,8 \pm 0,3$ & $1,34 \pm 0,01$ \\
\hline P8 & $35,0 \pm 0,1$ & $7,5 \pm 0,3$ & $1,09 \pm 0,01$ \\
\hline P9 & $50,5 \pm 0,2$ & $5,1 \pm 0,3$ & $0,66 \pm 0,01$ \\
\hline
\end{tabular}

During making and forming of ceramic masses it was noted that mixes with the highest amount of perlite dust (80 and $90 \%$ ) had poor formability. Moreover, these masses showed poor plasticity and tore easily, also after forming process moulders loose water and are ductile, which favours their deformation. Due to the high porosity of the perlite, the additive increases mixing water of masses. What is important, perlite does not increase the drying shrinkage, moreover it decreases this parameter. It means that perlite does not increase sensitivity to drying of ceramic masses.

\subsection{Parameters of ceramic sintered}

Parameters of ceramic sintered obtained are shown in the tables 3-5. The firing shrinkage, compressive strength, bulk density and thermal conductivity dependence of perlite proportion in ceramic mixes are shown in figures 1,2 and 3.

Table 3. Firing shrinkage, absorbability and open porosity clay-perlite ceramic materials.

\begin{tabular}{|c|c|c|c|}
\hline Symbol & $\begin{array}{c}\text { Firing shrinkage } \\
{[\%]}\end{array}$ & $\begin{array}{c}\text { Absorba } \\
\text {-bility [\%] }\end{array}$ & $\begin{array}{c}\text { Open porosity } \\
{[\%]}\end{array}$ \\
\hline [\% & $1,2 \pm 0,3$ & $11,8 \pm 0,2$ & $23,0 \pm 0,2$ \\
\hline P2 & $1,7 \pm 0,2$ & $12,2 \pm 0,2$ & $22,9 \pm 0,2$ \\
\hline P4 & $1,8 \pm 0,3$ & $13,6 \pm 0,3$ & $23,5 \pm 0,3$ \\
\hline P6 & $2,2 \pm 0,2$ & $16,6 \pm 0,2$ & $25,0 \pm 0,2$ \\
\hline P7 & $2,3 \pm 0,3$ & $19,8 \pm 0,4$ & $27,2 \pm 0,3$ \\
\hline P8 & $3,0 \pm 0,2$ & $25,3 \pm 0,3$ & $29,5 \pm 0,3$ \\
\hline P9 & $5,3 \pm 0,4$ & $49,4 \pm 1,5$ & $38,4 \pm 0,7$ \\
\hline
\end{tabular}

Table 4. Parameters of clay-perlite ceramic materials.

\begin{tabular}{|c|c|c|c|}
\hline Symbol & $\begin{array}{c}\text { Bulk density } \\
{[\mathbf{k g} / \mathbf{m} 3]}\end{array}$ & $\begin{array}{c}\text { Comp. strength } \\
\text { [MPa] }\end{array}$ & $\begin{array}{c}\text { Thermal } \\
\text { conductivity } \\
{[\mathbf{W} / \mathbf{m K}]}\end{array}$ \\
\hline 0 & $1,93 \pm 0,01$ & $36,9 \pm 3,5$ & $0,59 \pm 0,03$ \\
\hline P2 & $1,85 \pm 0,02$ & $32,8 \pm 2,0$ & $0,53 \pm 0,02$ \\
\hline P4 & $1,69 \pm 0,01$ & $26,6 \pm 1,8$ & $0,48 \pm 0,01$ \\
\hline P6 & $1,49 \pm 0,01$ & $18,4 \pm 1,4$ & $0,40 \pm 0,01$ \\
\hline P7 & $1,35 \pm 0,02$ & $16,2 \pm 1,5$ & $0,37 \pm 0,02$ \\
\hline P8 & $1,14 \pm 0,01$ & $13,3 \pm 1,5$ & $0,29 \pm 0,01$ \\
\hline P9 & $0,76 \pm 0,01$ & $8,7 \pm 0,7$ & $0,18 \pm 0,01$ \\
\hline
\end{tabular}

Table 5. Presence efflorescence and freeze thaw resistance for clay perlite ceramic materials.

\begin{tabular}{|c|c|c|}
\hline Symbol & efflorescence & $\begin{array}{c}\text { freeze-thaw resistance } \\
\mathbf{2 0} \text { cycles }\left(\mathbf{- 1 5} / \mathbf{2 0} \mathbf{0}^{\circ} \mathbf{C}\right)\end{array}$ \\
\hline 0 & + & + \\
\hline P2 & + & + \\
\hline P4 & + & + \\
\hline P6 & - & + \\
\hline P7 & - & + \\
\hline P8 & - & + \\
\hline P9 & - & + \\
\hline
\end{tabular}

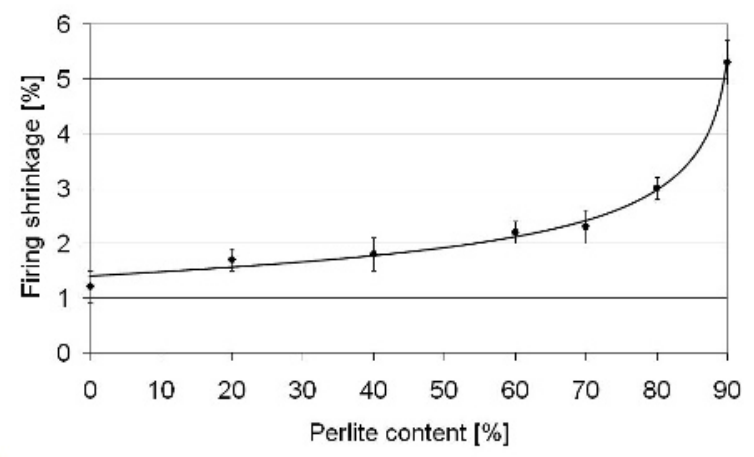

Figure 1. Firing shrinkage of clay-perlite ceramic materials.

Addition of perlite to ceramic materials significantly affects their parameters: increases open porosity and absorbability, reduces the compressive strength, bulk density and thermal conductivity. The greatest impact on compressive strength and absorbability occurs for a high proportion of perlite in ceramic masses, more than fourfold increase in absorbability and more than fourfold decrease in a compressive strength for sample P9. In addition, some similarities in the course of the bulk density and thermal conductivity curves as a function of perlite addition can be noted. Sintered with pearlite successfully passed freeze-thaw resistance research. Essentially, perlite increases the sintering shrinkage (Figure 1). This leads to the idea that when firing, perlite does not behave like an inert filler but actively participates in the process of sintering. 


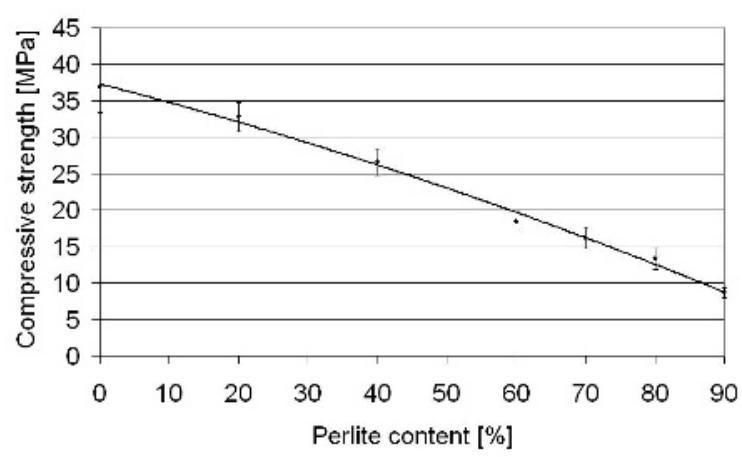

Figure 2. Compressive strength of clay-perlite ceramic materials.

\subsection{High-temperature microscope}

Last conclusion in 3.2 chapter is confirmed by the changes in the surface contour, registered during samples heating. Images from high-temperature microscope as well as changes in the surface contour are presented in figure 4.

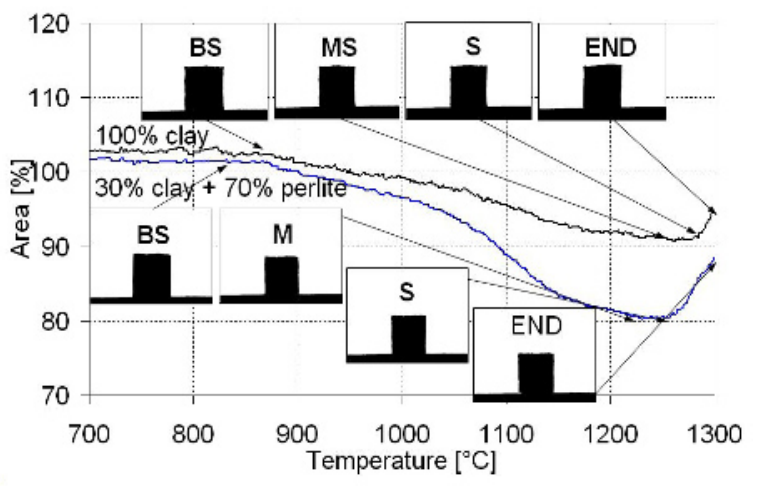

Figure 4. High-temperature microscope results for " 0 " and P7 samples.

Addition of perlite to loam caused slight decrease in the occurrence of characteristic temperatures, of about $30-40{ }^{\circ} \mathrm{C}$. It did not result in a narrow interval of sintering, that is the difference between the temperature of the end and the beginning of the sintering. Most importantly, the addition of perlite enhances the process of mass thickening during sintering, which is manifested by the larger changes in the surface contour of the samples. The possible reason for these differences is the melting action of perlite related to the high content of alkali oxides in this material.

\subsection{Phase composition}

In the figure 5 XRD patterns of P7 an "0" samples are shown.Quartz is the main phase component which is present in the sintered clay sample. The presence of hematite and dehydroxylized clay minerals from mica group is not excluded. Samples containing perlite shows the presence of plagioclases. Plagioclases are probably crystallized from glass contained in perlite. The intensity of the peaks of the phases coming from clay decreases proportionally to the mass fraction of perlite.

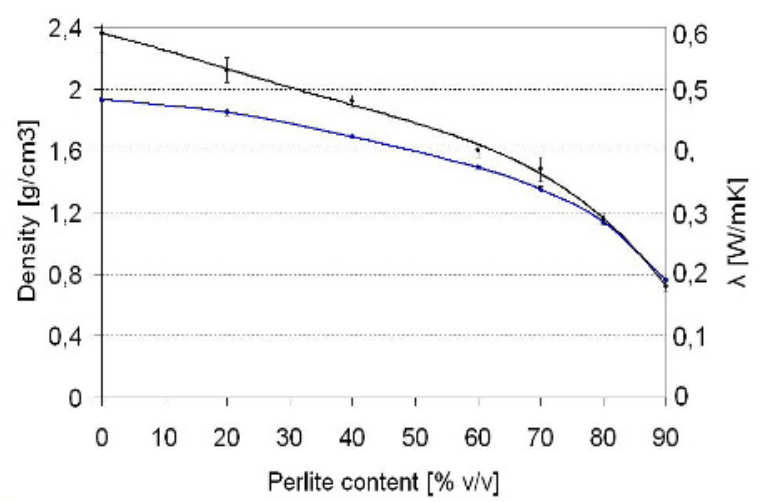

Figure 3. Bulk density and thermal conductivity of clay-perlite ceramic materials.

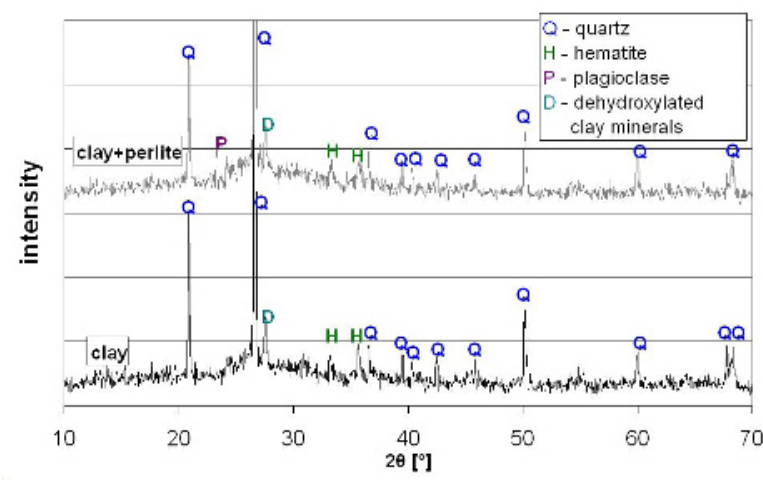

Figure 5. Comparison of XRD patterns of clay made sample and sample with perlite addition.

\subsection{DTA/TG analysis}

The results of DTA/TG measurements for starting materials and P7 ceramic mass are shown in the figures 6 and 7 . In the figure 6 approximate base curves were drawn alongside DTA curves.

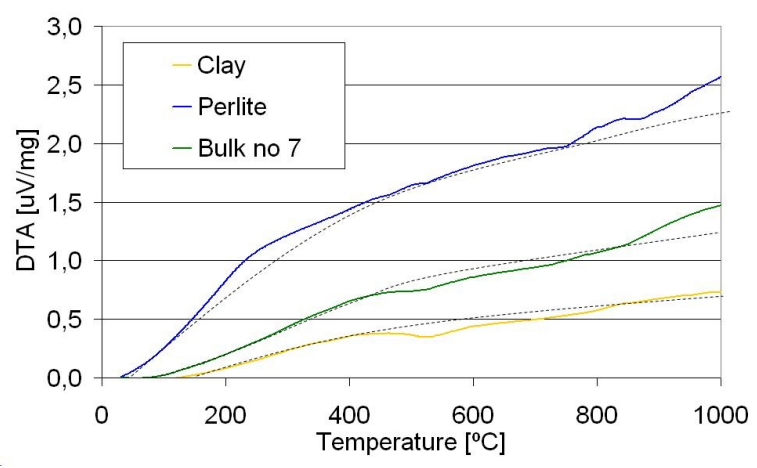

Figure 6. Differential thermal analysis for perlite, clay and $\mathrm{P} 7$ ceramic mass.

During heating process minerals which are present in clay are subjected to endothermic, dehydroxylation reaction at temperature range of $400-800^{\circ} \mathrm{C}$. This effect is accompanied by weight loss. A small exothermic effect connected with the beginning of sintering process can be observed above $900^{\circ} \mathrm{C}$. This effect isn't accompanied by weight loss.For perlite heated in the temperature range of $750-850^{\circ} \mathrm{C}$ characteristic, exothermic effect connected 
to glass transition can be noted, which is accompanied by subsequent, intensive exothermic effect connected to glass crystallisation and sintering. These two thermal effects aren't accompanied by weight loss. P7 mass curve is an approximate component of two curves.

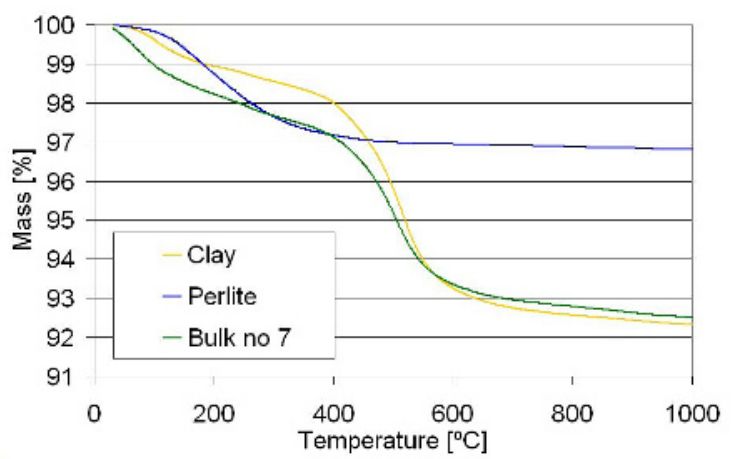

Figure 7. Weight change during heating for perlite, clay and $\mathrm{P} 7$ ceramic mass.

\subsection{Microstructure - scanning microscope}

In figures 8 and 9 microstructure images of ceramic samples P7 and "0" are shown using the same magnification.

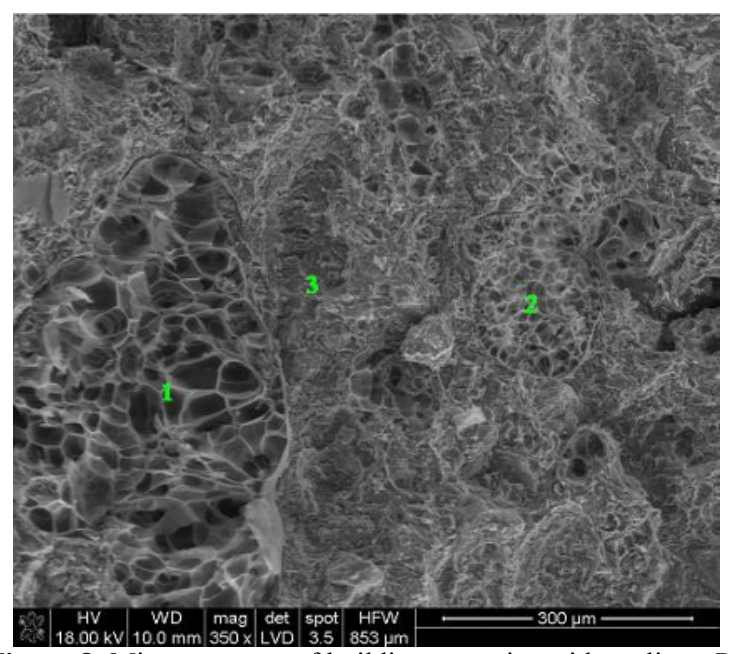

Figure 8. Microstructure of building ceramics with perlite - P7 sample

In P7 sample characteristic cellular perlite grains are clearly visible in point 1 and 2 in the figure 8 . They are dispersed in a matrix formed of grains of clay, which is shown in point 3 in the figure 8 . Perlite grains have clear but thin grain boundary and make an impression of a wellembedded in the clay matrix.

This is confirmed by the fact that, during the creation of the fractured samples, cracking occurred through perlite grains, but not on their grain boundary.

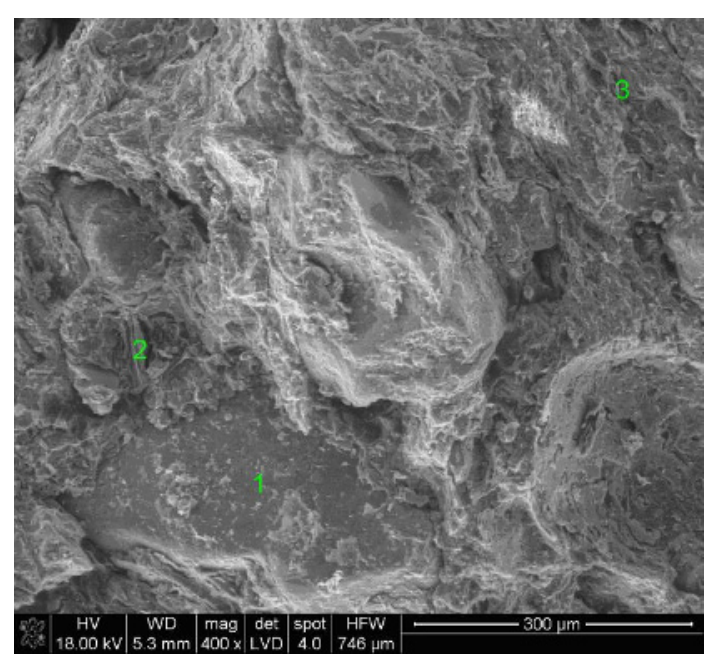

Figure 9. Microstructure of traditional building ceramics - " 0 " sample.

\section{Summary}

The results of this research indicated that dusty expanded perlite can be an interesting addition to the ceramic masses for building ceramics with improved thermal insulation. Due to its fine grains perlite can be used in a plastic ceramic masses. At the stage of forming perlite acts as opener for plastic mass and due to rheological parameters of mass, perlite under laboratory conditions can be used up to $70 \%$ by volume fraction. The main objective of this additive is to lower the thermal conductivity of ceramic material. About $70 \%$ perlite replacement by volume fraction resulted in reducing thermal conductivity of ceramic mass from about $0,59 \mathrm{~W} / \mathrm{m} \cdot \mathrm{K}$ to $0,37 \mathrm{~W} / \mathrm{m} \cdot \mathrm{K}$. Using a suitable cavity system can further improve the thermal insulation of building ceramics. Addition of perlite to ceramic mixes causes alteration of other operational parameters. It increases absorbability and open porosity, lowers bulk density and compressive strength. While lowering of bulk density is positive aspect, changes of other parameters is unfavourable, especially lower compressive strength. It can also be noted that the use of common pore-making additives such as sawdust and cellulose pulp aggravates strength of materials even more effectively.

Perlite takes an active role in sintering process, making its grains very well build into clay matrix, giving durable composite. It is probable that porosity of materials supplied by perlite reduces their strength by a small amount.

Addition of perlite to ceramic masses has other important advantages. This research showed that perlite as supplement reduces the formation of efflorescence. Moreover, perlite is the sound-absorbing material, so it can be expected that materials made from perlite shows improved sound-absorbing qualities. 


\section{References}

1. J. Nyers, L. Kajtar, S. Tomic', A. Nyers, Energy Build. 86, 268 (2015)

2. Regulation of the Polish Infrastructure Minister of 6 November 2008

3. V. Ducman, T. Kopar, Mater. Tehnol. 41(6), 289 (2007)

4. S. Krebs \& H. Mortel, TBI, 15(1), 12 (1999)

5. M. Sutcu \& S. Akkurt, Ceram. Int. 35, 2625 (2009)

6. J. Kocí, J. Madera, R. Cerný, Energy 83, 749 (2015)

7. V. Kocí, Z. Bazantová, R. Cerny, Energy Build. 76, 211 (2014)

8. F. Singer, S.S. Singer, Industrial Ceramics, (SpringerScience + Business Media B.V 1963),

9. W.V. Liu, D.B. Apel, V.S. Bindiganavile, Cement Concrete Comp. 53, 44 (2014)

10. A.G. Celik, A.M. Kilic, G.O. Cakal, Physicochem. Probl. Miner. Process. 49(2), 689 (2013)

11. A. Sarı, A. Karaipekli, C. Alkan, Chem. Eng. J. 155, 899 (2009)

12. S. Celik, R. Family, M. P. Menguc, J. Build. Eng. (to be published)

13. X. Yanjun, L. Rui, S. Haiping, J. Ran, Z. Jiayu, TOMSJ 9, 39 (2015)

14. Ch. Sadik, A. Albizane, I. Amrani, , J. Mater. Environ. Sci. 4(6), 981 (2013)

15. N. Burriesci, C. Arcoraci, P.L. Antonucci, G. Polizzotti, Mat. Letters 3(3), 103 (1985)

16. Ł. Kotwica, W. Pichór, W. Nocuń-Wczelik, J. Therm. Anal. Calorim. 123(1), 607 (2016)

17. E. Brylska, P. Murzyn, J. Stolecki, Ceramiczne Materiały Budowlane (Wyd. AGH, Kraków, 2014)

18. J. Małolepszy, M. Gawlicki, W. Pichór, E. Brylska, W. Brylicki, A. Łagosz, W. Nocuń-Wczelik, M. Petri, Z. Pytel, W. Roszczynialski, J. Stolecki, G. Malata, M. Reben, Podstawy Technologii Materiatów Budowlanych i Metody Badań (Wyd. AGH, Kraków, 2013) 